\title{
Correction to: BRCA1 and BRCA2 Germline Mutation Analysis in Hereditary Breast/Ovarian Cancer Families from the Aures Region (Eastern Algeria): First Report
}

\author{
Chiraz Mehemmai ${ }^{1,2,3} \cdot$ Farid Cherbal $^{1}(\mathrm{D})$ Yosr Hamdi $^{3} \cdot$ Abdelmoumene Guedioura $^{4} \cdot$ Wassila Benbrahim $^{5}$. \\ Rabah Bakour ${ }^{1}$. Sonia Abdelhak ${ }^{3}$
}

Published online: 5 March 2019

(C) Arányi Lajos Foundation 2019

\section{Correction to: Pathology \& Oncology Research https://doi.org/10.1007/s12253-019-00586-4}

The original version of this article unfortunately contained an error in the abstract section and Figure $2 \mathrm{~h}$ image.

\section{Abstract}

Page 1, under Abstract section, lines 11-12 should be rewritten as: Interestingly, we also detected a $B R C A 1$ exon 15 deletion in two unrelated young female TNBC patients with strong family history of breast/ovarian cancer.
The online version of the original article can be found at https://doi.org/ 10.1007/s12253-019-00586-4

Farid Cherbal

farid.cherbal@gmail.com

1 Unit of Genetics, Laboratory of Molecular and Cellular Biology, Faculty of Biological Sciences, USTHB, POB 32 El Alia, Bab Ezzouar, 16111 Algiers, Algeria

2 Faculty of Sciences of Tunis, University Campus 2092 - El Manar, Tunis, University of Tunis El Manar, Tunis, Tunisia

3 Laboratory of Biomedical Genomics and Oncogenetics (LRTI, IPT 05), Institut Pasteur de Tunis, University of Tunis El Manar, Tunis, Tunisia

4 LOBEM, Faculty of Biological Sciences, USTHB, Algiers, Algeria

5 Anti-cancer center of Batna, Batna, Algeria
Figure 2h

Pages 10, Symbol definitions of Family pedigree was missing in Figure $2 \mathrm{~h}$. The amended and corrected Figure $2 \mathrm{~h}$ is shown below.

Publisher's Note Springer Nature remains neutral with regard to jurisdictional claims in published maps and institutional affiliations. 


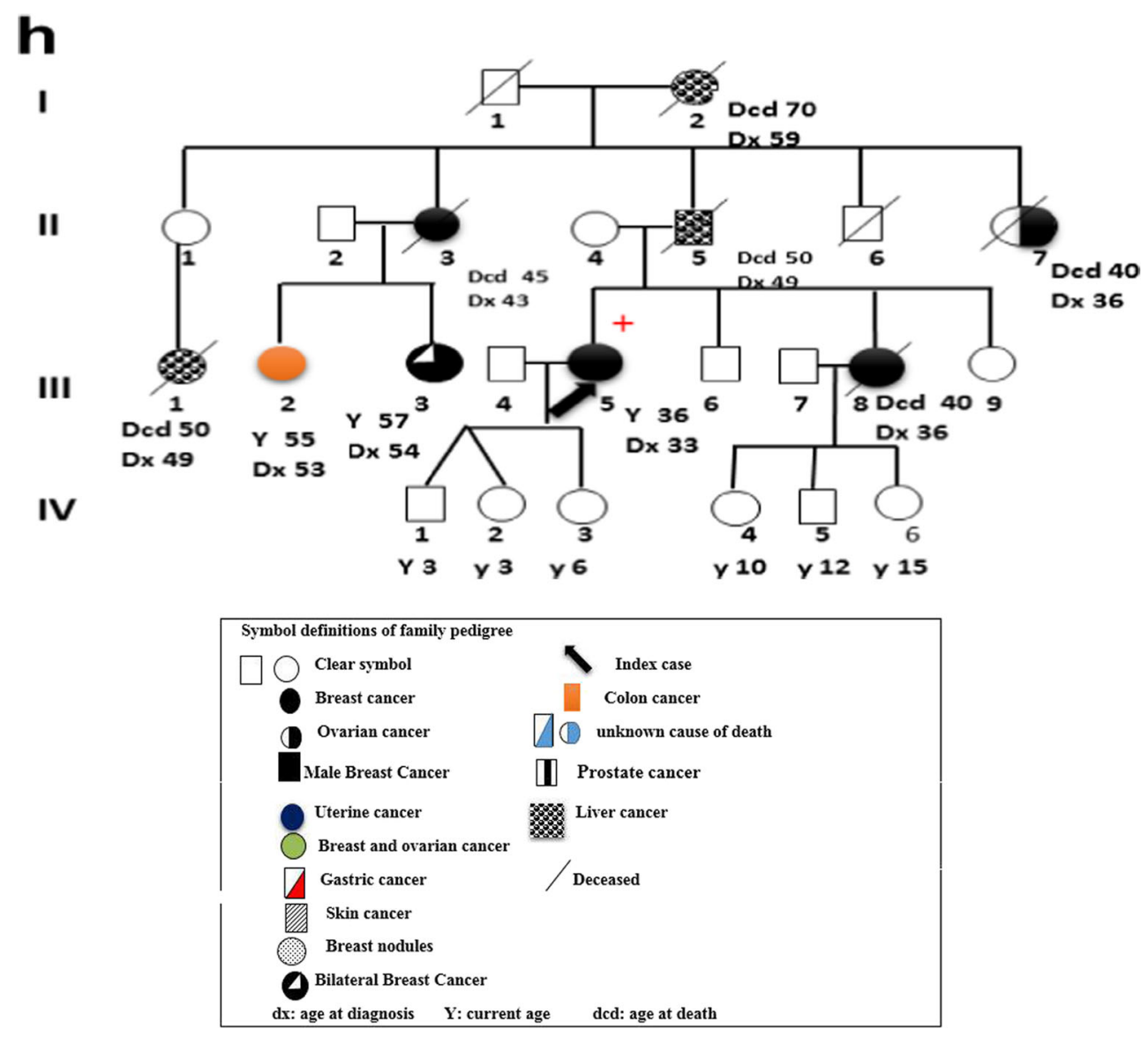

